\title{
Correction to: Dihydroartemisinin inhibits TCTP-dependent metastasis in gallbladder
}

\section{cancer}

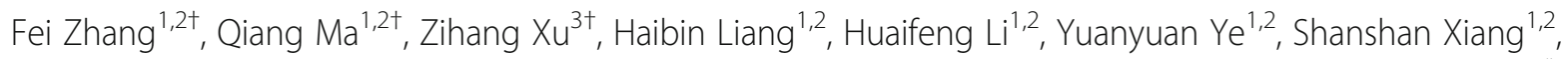
Yijian Zhang ${ }^{1,2}$, Lin Jiang ${ }^{1,2}$, Yunping Hu ${ }^{1,2}$, Zheng Wang ${ }^{1,2}$, Xuefeng Wang ${ }^{1,2}$, Yong Zhang ${ }^{1,2}$, Wei Gong ${ }^{1,2^{*}}$ and Yingbin Liu ${ }^{1,2^{*}}$

\section{Correction to: J Exp Clin Cancer Res http://dx.doi.org/10.1186/s13046-017-0531-3}

In the original publication of this article [1], there are mistakes in Fig. 3a and Fig. 3d.

The corrected Fig. 3a and Fig. 3d should be:

\section{Author details}

${ }^{1}$ Department of General Surgery, Xinhua Hospital affiliated to Shanghai Jiao Tong University School of Medicine, Room 517, Building 22, Xinhua Hospital, 1665 Kongjiang Rd, Shanghai 200092, China. ${ }^{2}$ Shanghai Research Center of Biliary Tract Disease, 1665 Kongjiang Road, Shanghai 200092, China.

${ }^{3}$ Laboratory of Integrative Medicine, School of Basic Medical Sciences, Shanghai University of Traditional Chinese Medicine, 1200 Cailun Road,

Shanghai 201203, China.

Published online: 03 September 2019

\section{Reference}

1. Zhang, et al. Dihydroartemisinin inhibits TCTP-dependent metastasis in gallbladder cancer. J Exp Clin Cancer Res. 2017;36:68. https://doi.org/10.11 86/s13046-017-0531-3.

\footnotetext{
*Correspondence: 13651819806@163.com; liuybphd@126.com

${ }^{\dagger}$ Fei Zhang, Qiang Ma and Zihang Xu contributed equally to this work.

${ }^{1}$ Department of General Surgery, Xinhua Hospital affiliated to Shanghai Jiao

Tong University School of Medicine, Room 517, Building 22, Xinhua Hospital,

1665 Kongjiang Rd, Shanghai 200092, China

Full list of author information is available at the end of the article
}

(c) The Author(s). 2019 Open Access This article is distributed under the terms of the Creative Commons Attribution 4.0 International License (http://creativecommons.org/licenses/by/4.0/), which permits unrestricted use, distribution, and reproduction in any medium, provided you give appropriate credit to the original author(s) and the source, provide a link to the Creative Commons license, and indicate if changes were made. The Creative Commons Public Domain Dedication waiver (http://creativecommons.org/publicdomain/zero/1.0/) applies to the data made available in this article, unless otherwise stated. 


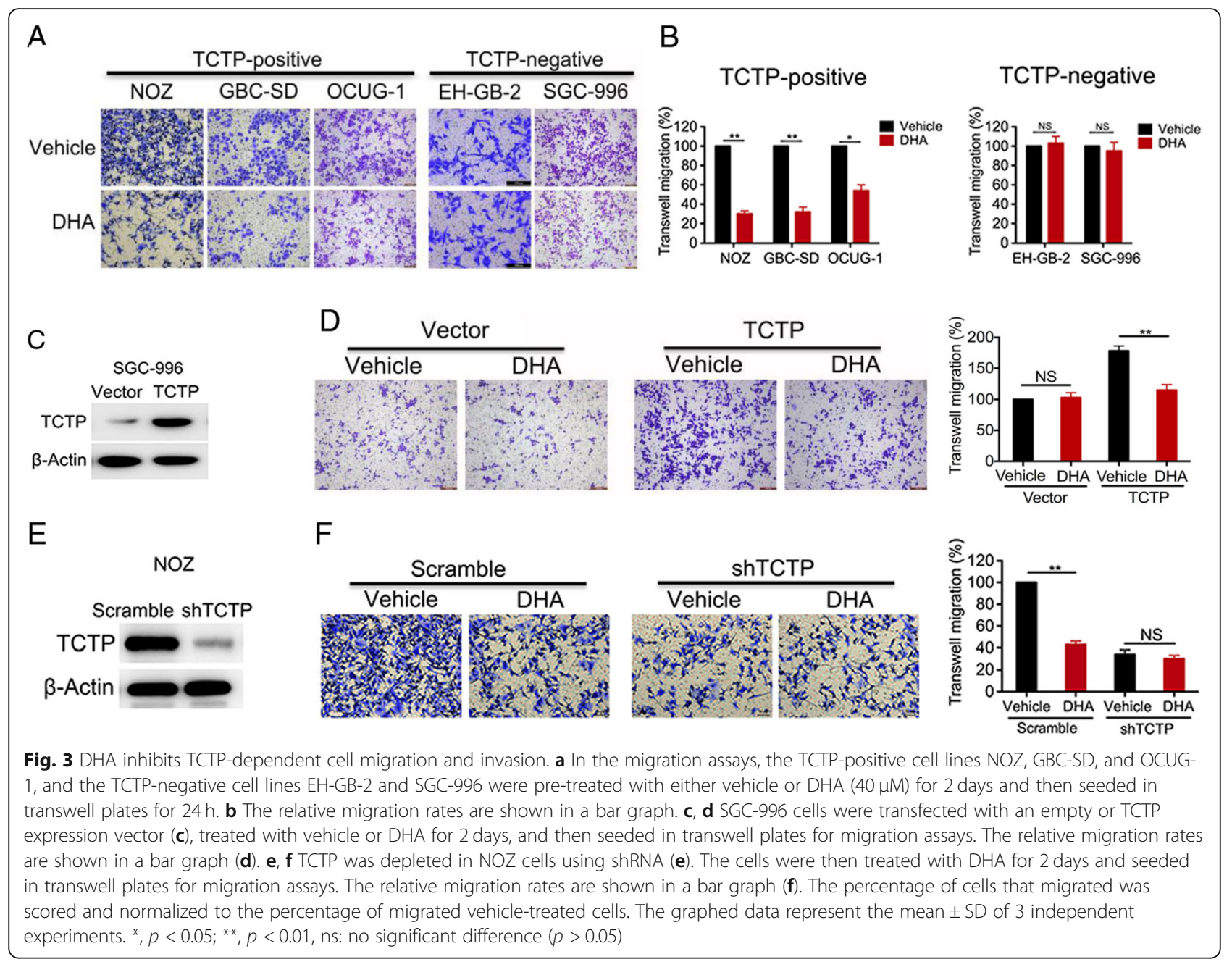

